\title{
THE "PSYCHOLOGICAL INTERPRETATION OF LANGUAGE."
}

\author{
By A. M. HOCART.
}

Current psychological interpretation of the language of savages-Its neglect of the social context-The social factors underlying the presence or absence of linguistic distinctions-The importance of historical factors.

THE doctrine seems fairly well established among comparative psychologists that savage languages are encumbered with useless distinctions which civilised man has learnt to discard and that they are poor in general concepts and rich in minute subdivisions of the species; dearth of ideas and superfluity of words are their failing.

This view may seem quite impregnable to the thinker at home, and, as it once seemed so to me, I cannot well blame those whose faith has never been exposed to that powerful dissolvent, experience of savage life. A few linguistic facts picked from various treatises and isolated from their vast context, which is no less than the whole life of the people, are just what tends to breed a false confidence of truth secured once for all Even eminent psychologists have fallen into this pitfall from which few pioneers escape; they will not therefore take it amiss if I give them a caution, and advise them to desist from the psychological interpretation of language unless they are conversant with the life and language of the people. Their knowledge must embrace everything that savages do, or think, or say; for how can we judge of a language till we know the uses it is put to and the thoughts it is required to express?

I do not wish to be dogmatic, or claim to set up a theory of language. I shall merely content myself with showing that some facts quoted in illustration of the orthodox theory can be subjected to a totally different interpretation. I shall take my text from the writings of Prof Stout. In his Analytic Psychology (1902, ii. 231) we read:

" The occurrence of distinctions of this kind in savage languages is sometimes regarded as a mark of their superior accuracy and subtlety, 


\section{The " Psychological Interpretation of Language"}

as compared with civilised tongues. Thus the missionary Williams speaks of the ' precision and perfection' of certain Polynesian dialects, and refers especially to ' nice distinctions in the pronouns."' Prof. Stout goes on to quote Williams: " A short time since, I was dining at Bath, when the lady of the house desired the servant to bring a plate, and, politely addressing me, said,' Put your bones upon the plate, sir.' Now, common as this expression is, it is certainly rather ambiguous. In the language of the Polynesians, however, there would be no such ambiguity, for they have two pronouns to express the difference, tooe and taoe; the former of which would be used if my own bones were meant; and the latter if those of the pheasant of which I had been partaking." Prof Stout remarks: "It certainly appears odd that a lower grade of intellectual development should be marked by superior nicety and precision of discriminative thought. The truth is that these distinctions, so plentiful in savage languages, are due rather to an incapacity for clearly apprehending identity in difference, than to a superior power of apprehending difference in identity....Similarly the savage mind has not pushed its analysis far enough to be able to reconstruct certain complex concepts out of simpler. Hence it simply takes the complex concept in its unanalysed totality and marks it by a separate sound."

Now, there is no doubt that the above distinction is in this particular case quite superfluous, but, until we know the whole language thoroughly, we cannot be certain that these two possessives do not sometimes express a vital difference, which we ourselves are compelled to cast into another form. The fact that words are superfluous in one case no. more proves that they are unnecessary duplicates than the overlapping of government departments in some matters would justify the suppression of any. Overlapping is a defect of languages, nay of all classifications, of which language is but one particular case.

Suppose a Fijian Williams were to visit England and, returning home, should laud to his countrymen the nice distinctions of which that country's language is capable, he might point out that for the Fijian sentence au tiko e na imbe, English has two-'-I am sitting on the mat,' or 'I am sitting in the mat,' as the case may be; Fijian is ambiguous, English is accurate, so accurate as to seat you in an armchair, but on a chair; Fijian has but one vague ' $e$ ' to serve all turns. A Fijian philosopher might rebuke the Fijian Williams, pointing out that this scrupulousness is excessive and that Fijian is superior in omitting to point out what every man can see for himself; for who can doubt the exact meaning of au tiko e na imbe ?. Would anyone 
hesitate as to whether I am sitting on the top or inside ? We do not require in and on to tell us how we use a chair and an armchair. Bather these distinctions, so plentiful in English, betray an incapacity for clearly apprehending identity in difference. Fijian is the more advanced since it has a word to express position in the abstract, whereas English has a different preposition for each several position, and has not yet evolved a common term for all ${ }^{1}$. Here a Fijian resident in England, who had read the Fijian philosopher and derived much benefit from his work, might interfere as a third party and argue: " It is true that in the examples adduced a single word would have done, but there are other instances in which it is not so; and it is true that language has been compelled to evolve several prepositions ' in," on,' ' at,' ' by,' eta, because white men make great use of tables, drawers, boxes, machinery, geometry, surveying, literary descriptions, which all require the most accurate definition, whereas we Fijians are but little addicted to description, and that of the baldest kind. Therefore they must keep a good stock of prepositions for technical use, which can also serve for the finest subtleties, even as we do in our own tongue. Thus a man who lies on his bed is taking a siesta; if in his bed, he has turned in to sleep or is invalided; we always lie on our beds. A motor is in town if it is in the road, and in the country if on the rood; we have no towns. There is all the difference between a nail on the table and one that is in it; we had no tables till the white man came. Having thus evolved, by some process or other, these particular forms, the white men have apportioned among them the whole realm of position and have left no room for a general term, no indefinite, indeterminate sphere; for they, like all other people, speak for practical purposes and not in order to satisfy psychologists that they possess the analytic faculty. No matter, therefore, whether position is obvious from the context or not, you must define it, because none but definite terms are at hand; we know perfectly well how a man is sitting if a mat is his seat, yet to substitute on that ground in for on would shock the genius of the language by its incongruity, because in has a determinateness incompatible with the present case, and white men do not keep an indefinite preposition merely for the pleasure of it." Thus our Fijian third party; we must try and be as fair as he.

I do not know the language of the Cook Islands, but I do know

\footnotetext{
${ }^{1}$ We are compelled to say: Dogs are not allowed in or on this car; the Fijian $e$ na ngginggi would cover all cases.
} 


\section{The " Psychological Interpretation of Language "}

Fijian, which has exactly the same idiom. Only the number of Fijian possessives is four, not two, and it would seem a hard task to defend them all; there is one for parts of the body (-nggu, etc.), one for property (nonggu, etc.), one for food (kenggu, etc.), and one for drink (menggu, etc.). Better plead guilty at once. But Fijian refuses to plead guilty and invokes the following cases in its discharge: na ndakunggu is 'my back,' but nonggu ndaku is 'my sister-in-law,' because I turn my back to her. $E$ yasanggu is 'beside me,' but $e$ nonggu yasa is 'in the side of the house which it is my duty to build.' Mena kai is 'his mussel to eat' (or rather 'to drink,' as the Fijian says); nona kai is ' his shell' which he, or rather she, uses to split leaves for mat-making; kena kai is 'his marks' or 'points,' the tokens of which were once presumably shells. Waina is ' its juice' or ' milk'; nona wai is ' his medicine' which he owns as a leech ; kena wia is ' the medicine for that disease'; mena wai is ' water for him to drink,' or ' medicine for him to take'.' Kalou ni nona and kalou ni kena are both ' spirits of his,' but one is a spirit of his property, who brings him abundance of fabrics (iyau), and the other is a spirit of his food (kakana), who makes him successful in fishing, or hunting, or planting. Here we touch upon the influence of social customs upon language, for there can be little doubt that the separate existence of the property and food pronouns has been strengthened by the fundamental contrast between fabrics and food which are the two great categories of Fijian activity and social intercourse.

Moreover, to isolate, as is usual, the word from its context is certainly unfair to the language; it seems ridiculous to say nonggu kote for 'my coat,' but kenggu mandrai for 'my bread'; but let us take whole sentences and the matter wears a different aspect: kauta mai nonggu kote is 'bring my coat,' while kauta mai na kenggu mandrai is ' bring me some bread,' or' bring me my portion of bread.' If English has different constructions Fijian is entitled to different pronouns; they merely use different means to do the same work.

So far from occupying a sinecure the food possessive -has gradually absorbed new functions and greatly extended the sphere of its activity: $a$ nona nggase is ' his old man,' ie.' father'; but a kena nggase is ' the elder one.' Fijian has for historical reasons, as yet unknown, developed four possessives among which it has apportioned the whole sphere of possession; the frontiers are often arbitrary; indeterminate cases are treated as if determinate; but what of that ? Is it not better than to

${ }^{1}$ This example is given in part by Hazlewood in his Fijian Dictionary. 


\section{HOCART}

invent a fifth pronoun for the sake of logic ? Are the yams I have planted nonggu or kenggu ? I may possibly never eat them, and shall certainly never eat them all, but as I planted them for me and my family to eat we shall make it kenggu. Language is no hair-splitter; it would sooner be inaccurate than stock words for rare cases. So long as in ninety-nine cases out of a hundred there can be no doubt about the right possessive, the hundredth case can take care of itself We do not keep a generalised preposition simply because we may not be certain at times whether a thing is in or on a box, and whether the plate in question is a soup plate in which, or a flat plate on which, we put food.

In Central Asia they have a name for each kind of horse according to the nature and distribution of its colour, but no word for a horse in general $^{1}$. This seems a triumphant proof of analytic weakness in savages; but hold! Do we know everything that an Asiatic thinks, says or does in regard to horses? Tell us that and we may judge; for colour may be all important to them: they may have superstitious or physiological ideas about it, or it may be a privilege of rank, or the price may depend upon it; in fine there may be a thousand and one reasons why colour should make a difference. Do we not use black horses for funerals, and white ones for a coronation ? We have quite a number of colour terms reserved almost exclusively for horses, such as roan, dappled, bay, chestnut; lately I came across a French word for a horse with a black head. I think I am right in saying that a horsey person never speaks of a stallion or a mare as a horse.

We may go through life without ever noticing that whereas we have words for a bull, a cow, an ox, a calf, a heifer, etc., we have none for the species except cattle which is collective; in fact the French have had to invent bovidé for neutral cases in archaeology ${ }^{2}$. Does that prove that we simply take "the complex concept in its unanalysed totality?" The reason merely is that the bovidé is the most important domestic animal, and furthermore that difference of sex makes all the difference in practical use: the mare, the horse, and the stallion are all used for riding, but a bull is kept for breeding, an ox for work and meat, a cow for milk, and the calf gives a special kind of meat. It is only when they arc mingled together in a crowd that we need the general term 'cattle.' In the rare cases of uncertainty (and I have

1 See Radloff, Zeitsch..f. Ethnol. 1871, iii. 285.

2 My attention was drawn to this word by Mr Marett 


\section{The " Psychological Interpretation of Language "}

never yet come across one) there is no harm done if the beast is called a cow and turns out to be an ox. It would be interesting to find out how a slum boy uses the words.

Returning to the language of savages after the sobering experiences of our own, we shall find that the same rules hold good of them. Here is a case which warns us how differences, slight in our eyes, may carry with them a whole train of practical differences for the savage. The Solomon Islands possess a most useful nut, the kanary, which engrosses much of the islanders' interests and fills much of their existence. In those parts investigated by Dr Rivers and myself they distinguished two kinds: the vino and the ngari; in our eyes it was merely a difference of size, and we might never have considered them otherwise than as large and small specimens had not the natives given us the two words. Yet closely related as they are, they have no common term. Had we proceeded no further, we might have ascribed this deficiency to " an incapacity for clearly apprehending identity in difference." But is it reasonable to suppose that an identity so glaring could not peep through the thin veil of differences ? Why should we, white men, start from identity to end in a perception of differences and the savage work in the opposite direction ? If instead of contenting ourselves with a vocabulary we inquire into the practical uses of the kanary, we shall be compelled to justify the savages. We found that from trifling differences sprang a host of momentous ones-technical, commercial, and religious: the seasons of the two species do not coincide; they are gathered differently, because the branches of the vino will bear a man and the ngari will not; they are cracked differently because the ngari is larger, and in one island this was the object of a taboo; they are preserved differently: the vino is pounded and made into a package, then smoked; the ngari is smoked in the shell; the vino coming early supplies the offerings of first fruits, while the ngari, being abundant, is used for the later smoked-nuts festival; in certain diseases the one is tabooed as food and the other not; the two, in fact, are only identical in the kitchen, and therefore they have but one word for the roasted kernels and puddings of either. A common term would normally be as useless to them as bovidé to all of us who are not scientific men.

Take the coconut again: every stage of its growth has a name, and a South Sea language may recognise as many as nine. We need neither exclaim over the richness of their language nor decry their analytic powers. They have done but what we should have done if coconuts grew in Europe. The reason is simply that, whereas other 
fruits are either ripe or unripe, each stage of the coconut's growth makes a practical difference: in one it is not edible, in the next it may have milk but no flesh; the shell of one is edible, later it is too hard; as it approaches maturity it is drink for man and food for pigs; later it is prized as food and despised as drink; the stage of development has to be ascertained by Slipping the nut, because it is opened differently according as the shell is hard or soft. So necessary are these words that the white resident will inevitably adopt into his English such as are of practical use to him.

A great many languages that use the classificatory system have a word for elder and one for younger brother, but none for both; but all students of kinship will know that seniority is rich in social consequences; a man must always know who is his senior and who his junior, and is always able to specify which ; he has a collective term for both, however, since a collection of brothers contains elder and younger. On the other hand, we have a word for brother and one for sister, but none that leaves the sex indifferent; savages have such a word ${ }^{1}$.

Take again the particles quoted by Prof. Stout (op. cit., p. 230). Are distinctions between " to cut in two with a knife, to shoot off, to cut off with an axe, to break off with the foot, to break off with the hand, to bite off," so superfluous that a special word for each argues a low mental development ? especially if we do more justice to them by translating them: " to cut in two with a knife, to shoot off, to chop off, to stamp off, to snap off, to bite off." In dealing with such people we must always remember that they do not live in studies or in towns, retaining a purely theoretic interest in many kinds of action ; they are all handy men and jacks of all trades,- - handy men in the literal sense, for they have no machinery but do everything by hand; modes of action, therefore, which are unimportant to us are most weighty to them. Thus a yam is not slashed at (taya) except by accident or malevolence, but it can be cut lengthwise (kola) or crosswise (suvi), a matter not indifferent in planting; expert planters slit (sei) them part of the way down; before cooking it may be cut up or chopped up (dhembe) to boil. To appreciate their point of view one must have tried to live their life, or at least watched them at their work and got interested in the same; failing that, let a man take to the sea_or go a-farming and he will soon find that each mode of life has its minute vocabulary that is as necessary as it is rich.

${ }^{1}$ Cf. W. H. B. Rivers, "The Primitive Conception of Death," Hibbert Journal, 1912, x.401. 


\section{The " Psychological Interpretation of Language"}

I shall leave American Indian particles alone, as I know nothing about that language. I will point out only that Fijian also is rich in them though it uses them for different purposes, but no one will question the need of them: nunu-va means to dive for a thing; nunu-vaka means to dive with it. If English finds it necessary to use two different prepositions, a savage language has the right to use two suffixes. A Fijian taking the same standpoint as Prof. Stout might, in fact, maintain the superiority of his own language since English has, for instance, a different root to express every idea connected with sight, but no general term, whereas his own tongue has a term as wide as could be desired, which is particularised by means of suffixes and reduplication, thus:

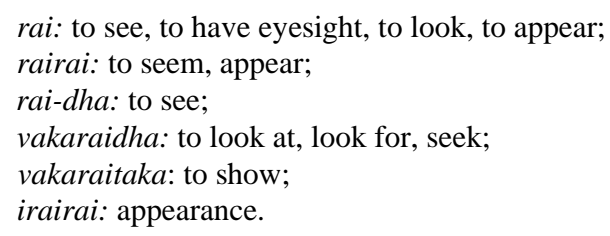

In fact Fijian words are often so purged of all concreteness that we have not their equivalent for abstraction in English. To the above rai we can add rongo, which designates both sound and hearing; ndre is the action of pulling in the widest sense, without definition of active or passive; the addition of particles defines it as pulling a thing, or being pulled, pulling against each other, confirming, difficult, obstructing, etc. What a European, continually using a savage language, wearies of is not the excess of minute distinctions, but the vagueness of concepts so wide that they cannot convey the distinctions which he takes an interest in and which alone make conversation worth while to him: he cannot speak of trees without including all plants; he cannot take the birds and leave the bats and butterflies; he has but one word to use whether he is discussing ambition, rivalry, or jealousy: in translating lialia into English he must consider whether mad, foolish, simple, idiotic or ignorant will suit the context, because English has no word to express intellectual deficiency in general; after trying ' words,' ' sayings,' ' speeches,' to render vosa he may have to adopt ' maxims,' and yet be dissatisfied because it is too precise. The language in the end seems so poor to him, so destitute of specific terms, simply because he insists on saying things that he takes a detailed interest in, but not the Fijian, and wants to be minute where a Fijian is quite content with handling in gross. Let him turn to planting, to handicrafts, and 
war, and he will find as precise and minute a vocabulary as he may require.

Admitting that savage languages are addicted to particular terms and neglect the generic, yet it is strange that this should be cast at them as a reproach when it constitutes one of the chief excellencies of style. Is it not the rule always to use the lowest possible genus, and does not insipidity result from the use of a general term when there is a more particular one ? Good prose is to a great extent the use of the exact word, and the exact word is the narrowest that will fit.

Sometimes, indeed, the particular term is so unusual in certain contexts that the general one is not allowed even where it would be the right one. We cannot say to a South Sea Islander, " Come and see me after lunch, or tea, or dinner, or supper"; because all South Sea meals are identical and none of these terms will describe them; yet if we try 'after meal' the King's English takes offence; the only loophole of escape is to use the Polynesian kaikai or the slang ' grub.' Dr Rivers points out to me that of old a man might have said 'after meat'; doubtless meals were less highly differentiated then, but according to the orthodox theory we moderns must be going backwards.

Learning a language we use a dictionary, but studying it we must set it aside and observe the practical use of words. For it is the business of dictionaries to define per genus et speciem; they must therefore make words represent genera, which, in actual practice, are specific; we are therefore apt to imagine that we are richer in general terms than we really are. A dictionary may define 'bowling' as 'a mode of throwing,' but the rules of the game oppose them to one another, and a man who speaks of a bowler throwing the ball either does not know the game or means it is noball. A Martian might draw thence interesting conclusions regarding the analytic powers of French and English; but we know it is all a matter of playing or not playing cricket.

A cock crows, a hen cackles, a pigeon cooes, a jackdaw caws, other birds sing or chirp or warble, but they cannot cry as they all do in Fijian. Is Fijian therefore more advanced in ornithology? On the contrary, it is because they take no interest in birds that they have but one word; our variety of terms is the outcome of abundant bird life, farmyards, eggeating, shot-guns, singing-birds, pets and poetry. Dictionaries do require a common term for the purposes of definition; they are allowed to say that crowing is the cry of the cock, but fancy our reciting: " This is the cock that cried in the morn." 


\section{The "Psychological Interpretation of Language"}

Wool is a species of hair, but no one ever speaks of sheep's hair. The French crin can be subsumed under poil, but in practice they exclude one another: a poil de cheval comes from any part of the body except the mane and the tail.

If I may put it paradoxically, the very indefiniteness of a term constitutes its definition ; the fact that it is general makes it quite plain that it is not particular: if a bowler throws, he does not bowl; if a pigeon cries it does not coo; say a hair, and, whatever it may be, it is not wool. Logic assigns one conceptual area to one word, and then subdivides this area into narrower concepts and so on, as Europe is divided into states, states into provinces, provinces into districts. But practice gives to one word the vast uninteresting, indefinite part of a concept and to others the various interesting, definite, analysed portions; for instance, it classifies into throwing in general and bowling, jerking, pitching, flinging, hurling in particular; the whole class is called after its widest member throwing. It is as though our geography should distinguish England, Scotland, Wales, and Ireland, and lump together the unanalysed residue as Europe; yet when we wished to speak of the continent and the British Islands as a whole we also called it Europe.

If our dictionaries, excellent for their purpose, are quite inadequate for the psychological interpretation of language, how much more so are vocabularies of savage languages, which, even when they are not poor, cannot in the nature of things give more than approximate equivalents of native terms. Of the injustice thus done to savage languages here is a striking instance: Williams ${ }^{1}$ says Fijians have a word for clapping hands lengthwise, and one for clapping crosswise ; now, these definitions of sausau and dhambo respectively are sufficient for identification, but do not by a long way exhaust the whole connotation of these words: sausau is a rapid, high-pitched clap used to mark the rhythm in dances; dhambo is a slow, hollow clap which expresses respect for a superior; Fijian no more requires a common term for both than we do for bowing and playing the piano.

Much unnecessary admiration has in consequence been spent upon the supposed richness of savage languages and many undeserved strictures. The same Williams counts fourteen Fijian words for cutting. He does not give the fourteen, but here are as many as I can think of, or find in Hazlewood's dictionary:

ta, sele, koti, musu, dhembe, kola, suvi, sivi, se, tava. ${ }^{1}$

Fiji and the Fijians, 161. 
Now it is very true that all of these words are sometimes translated cut, but equally true that they are not confined within the limits of that word: they all overlap with it, but all overlap too with other English words, so that by a different arrangement we can prove the superiority of English, since to every one of the words we have quoted correspond two or three of ours, thus :

\begin{tabular}{|c|c|c|c|}
\hline Sele & $\begin{array}{l}\text { to cut } \\
\text { to carve } \\
\text { to amputate } \\
\text { to castrate }\end{array}$ & koti & $\begin{array}{l}\text { to cut } \\
\text { to snip } \\
\text { to shear } \\
\text { to clip }\end{array}$ \\
\hline tá (ta) & $\begin{array}{l}\text { to cut } \\
\text { to chop } \\
\text { to hew } \\
\text { to fell } \\
\text { to hack } \\
\text { to notch } \\
\text { to slash }\end{array}$ & dhembe & $\begin{array}{l}\text { to cut across } \\
\text { to break off } \\
\text { to cut up } \\
\text { to hash } \\
\text { to mince }\end{array}$ \\
\hline kola & $\begin{array}{l}\text { to cut }\} \\
\text { to slice }\} \text { lenghtwise }\end{array}$ & se & $\begin{array}{l}\text { to rip } \\
\text { to split } \\
\text { to cut in twain }\end{array}$ \\
\hline suvi & $\begin{array}{l}\text { to slice }\} \\
\text { to carve }\} \text { crosswise }\end{array}$ & & along the fibre \\
\hline sivi & $\begin{array}{l}\text { to hack } \\
\text { to chip } \\
\text { to adze }\end{array}$ & tava & $\begin{array}{l}\text { to cut } \\
\text { to operate } \\
\text { to slit }\end{array}$ \\
\hline
\end{tabular}

That is twenty-one to ten: where is the richness of Fijian ? and which of the two is more zealous in expressing minute distinctions? such as ' hash' and ' mince,' ' snip' and ' clip.' It may be objected that English has a general term as well as particular ones. Has it? Does a sculptor cut wood, a surgeon cut his patient ${ }^{1}$, or a shepherd cut wool ? If cut is accepted as the genus, yet Fijian is only inferior in having two terms, ta and sele, instead of one, as we may expect from a vocabulary framed at a time when cutting with a bamboo knife and cutting with a stone axe were as radically different as chopping and sawing: now that steel knives can be used in both ways we are apt to miss the point of this dualism. Thus we require a knowledge not merely of the present conditions of the race, but also of their primitive technique.

We have so far reasoned as if language sprang, Minerva-like, from

${ }^{1}$ Dr Rivera points out that he does 'cut,' bat only in a highly technical sense, namely for stone. 


\section{The " Psychological Interpretation of Language "}

the human brain, ready to meet any contingency. But as a matter of fact, each stage of a language is conditioned by an antecedent stage. When we have proved that a word is useful, we have explained its survival but not its origin. If we convict it of uselessness, we may safely predict its death; but the fact that it is useless now, proves nothing about the mental state of the people who still use it: it may have been adapted to a primitive technique, now disappeared; even the fact that it always was useless proves nothing at all, because it may have been forced upon the people by the material at their disposal. Each generation is provided with a certain material to work with, and it makes the best of it; the best may not be very good, but that is no more a proof of low mental development than the use of stone implements is, where iron was never heard of. Fijian supplies us with a good example: it has two main prepositions for our ' in': $e$, in the same place as the speaker, and mai, in another place; thus a Fijian says $e$ Viti for ' in Fiji,' but mai Samoa. Now these prepositions are certainly demonstratives in their origin: $e$ is still used to mean here, and mai for yonder; it would appear then that to express ' 1 am in Fiji,' the Fijian began by saying: 'I am here Fiji'; that was out of question when speaking of Samoa, for Samoa is not here but there; he had therefore to say: ' He is there Samoa.' How far Fijians are still conscious of the proximity and distance attached to $e$ and mai in their role of preposition we cannot tell; when that consciousness dies out we may expect to see $e$ ousting mai or mai ousting $e$, unless the Fijians have died out first.

It is strange indeed that historical conditions, the importance of which is so obvious in explaining our own language, should be completely ignored in the psychological interpretation of savage languages. Suppose a savage accused us of having more words than ideas and quoted in his support ' commence' and ' begin,' ' end' and ' finish,' 'food' and 'nutriment,' 'God' and 'Deity,' 'image' and 'idol,' etc.- " My dear Sir," we should protest, " read your history before you talk. Then you would know that England was conquered by the Normans who spoke French, and that our medieval scholars borrowed many words from the Latin and Greek. Some of these immigrant duplicates are kept up by pedantry; others, like ' nutriment have received a scientific meaning, or, like ' beef and ' mutton,' a practical use." But who knows how many invasions, conquests, migrations, have not swept over Africa, Oceania and America ? Yet most English students have hitherto gone on the tacit assumption that languages grew up among savages just like a plant out of the soil, and they confidently explain psychologically 
a plethora of words, which, when it exists at all, may be due to mixture of races. The four numbers of Fijian they would interpret as a mark of intellectual shortcoming; but it is most likely that they are the outcome of invasions; for neither dual nor trial can be explained by Fijian laws of sound changes, and the dual is in the third person but a replica of the plural. Without entering into details we may represent what may have happened thus: one people said

'he' for 'one,'

' they two' for ' any number'; the

other said:

$$
\begin{aligned}
& \text { ' he' for ' one,' } \\
& \text { ' they twain' for ' two,' } \\
& \text { ' they three' for ' three or more.' }
\end{aligned}
$$

Coalescing they produced:

singular,' he';

dual,' they twain';

trial,' they three';

plural,' they two.' The abundance of numbers thus

developed by accident has been made use of: the trial expresses a small

group - the gens, the household, the passengers on a canoe, etc.; the plural expresses an unlimited number - keitou is ' we,' the members of the gens, keimami is ' we,' Fijians.

The whole historical argument seems so obvious that we are almost ashamed to insist upon it, and hasten to close it with this question: Is it possible from the tangled skein of savage history to unravel the mental processes that have moulded the language and apportion exactly the influence of mind and the influence of material ? Certainly not at present; historical research may at any turn belie the psychological inference. A further question is: Would it be the duty of linguistics and ethnology to do so ? If the example of geology can be safely invoked we shall answer no: geology does not seek for new physical laws; it applies those derived from the observation of nature to the data of the globe's crust in order to reconstruct the history of the earth. Such also seems to be the function of ethnology, of which linguistics is but a branch : from the facts of language, customs, and religion, to restore the past history of man according to known laws, known because we can see them happening around us, or trace them in documents. Phonetics has begun to achieve this, and there is no reason why the whole of philology and ethnology should not.

(Manuscript received 5 June, 1912.) 